\title{
Developmental Regulation of Apoptosis in Dorsal Root Ganglion Neurons
}

\author{
Michael A. Vogelbaum, Jianxin X. Tong, and Keith M. Rich \\ Department of Neurological Surgery, Washington University School of Medicine, St. Louis, Missouri 63110
}

The survival of dorsal root ganglion (DRG) neurons, both in vivo and in vitro, is dependent on the availability of nerve growth factor (NGF) for a transient period early in development after which these neurons become independent of NGF for survival. The precise molecular mechanism by which developing DRG neurons gain independence from NGF has not been determined. We used an in vitro model of DRG neuronal development to test hypotheses that independence from NGF in mature DRG neurons could be caused by developmental regulation of either elements of the NGF withdrawal signal transduction pathway or of proteins important for activation of the apoptosis output pathway.

Interruption of phosphotidylinositol-3 kinase activation, by treatment with the specific inhibitor LY294002, resulted in apoptosis in immature but not mature DRG neurons in a manner similar to that observed with NGF withdrawal. Further downstream along the signal transduction pathway, c-JUN phosphorylation occurred in both immature and mature DRG neurons after NGF withdrawal or treatment with LY294002, despite the fact that the older neurons did not undergo apoptosis. In contrast, the ratio of expression of the proapoptotic gene bax to antiapoptotic gene $b c l-x_{\mathrm{L}}$ was many times higher in immature than mature neurons, both in vivo and in vitro.

Taken together, these results strongly suggest that developmental regulation of NGF withdrawal-induced apoptosis in DRG occurs via control of the relative level of expression of members of the $b c l-2$ gene family.

Key words: phosphotidylinositol-3 kinase; c-JUN; bcl-2 gene family; dorsal root ganglion; nerve growth factor
Development of the nervous system requires the selective elimination of up to one-half of the total number of neurons produced during early fetal life (Oppenheim, 1991). Removal of excess neurons via apoptosis is a highly controlled, physiological phenomenon (Kerr et al., 1972; Oppenheim, 1985). Target-derived neurotrophic factors, the prototype of which is nerve growth factor (NGF), mediate the selection for survival of neurons of neural crest origin, including those in the dorsal root ganglia (DRG) (Johnson et al., 1986; Oppenheim, 1991). DRG neurons are sensitive to loss of NGF support during a transient period in utero. Autoimmunization of maternal guinea pigs against NGF produces up to $85 \%$ loss of DRG and loss of nearly all cervical sympathetic neurons in the offspring, which results in a profound loss of sensory and sympathetic function (Johnson et al., 1980). Exogenous supplementation of NGF prevents developmental cell death of DRG neurons that innervate the chicken wing bud (Hamburger and Yip, 1984). Postnatally, DRG lose their sensitivity to interruption of NGF support; however, sympathetic neurons remain dependent on NGF for survival (Rich et al., 1984).

As is the case in vivo, embryonic DRG neurons initially require NGF for survival in vitro. Withdrawal of NGF from embryonic day 15 (E15) DRG neurons within the first $10 \mathrm{~d}$ in culture results in an apoptotic death. However, by $21 \mathrm{~d}$ in culture the majority of

Received May 27, 1998; revised Aug. 11, 1998; accepted Aug. 20, 1998.

This work was supported by National Institutes of Health Grants 5 R01 NS29477 (K.M.R.) and PHS 1 F32 NS10295 (M.A.V.). We thank Dr. Eugene Johnson for his generous contribution of resources and his review of this manuscript. We also thank Dr. Rajishiri Perugu for technical assistance.

Parts of this paper were presented in abstract form at annual meetings of the Society for Neuroscience (1996 and 1997).

Correspondence should be addressed to Dr. Keith M. Rich, Department of Neurological Surgery, Washington University School of Medicine, 660 South Euclid Avenue, St. Louis, MO 63110.

Copyright (C) 1998 Society for Neuroscience $\quad 0270-6474 / 98 / 188928-08 \$ 05.00 / 0$ these neurons survive for long periods of time without NGF support (Tong et al., 1996). A similar age-dependent sensitivity of rat DRG neurons to apoptosis induced by ionizing radiation has also been observed (Tong et al., 1997). The precise molecular mechanism by which developing DRG neurons lose their sensitivity to apoptotic stimuli has not been determined.

The intracellular pathways that mediate the response of DRG neurons to NGF withdrawal can be divided into two general parts: a signal transduction (i.e., signal input) pathway and an apoptosis (i.e., signal output) pathway. Important members of the signal transduction pathway include phosphotidylinositol-3 kinase (PI3K) and c-JUN (Ham et al., 1995; Yao and Cooper, 1995). The apoptosis pathway requires the presence of BAX (Deckwerth et al., 1996), a proapoptotic member of the bcl-2 gene family and may also be controlled by the levels of other members of this gene family. Loss of dependence of DRG neurons on NGF potentially could be manifested by developmental changes in the signal transduction and/or apoptosis output pathways.

We tested the hypotheses that independence from NGF for survival in mature DRG neurons could be caused by either developmental upregulation of PI3K activity, interruption of NGF withdrawal induced activation of c-JUN, or a developmental change in BAX and/or BCL-X expression that downregulates the apoptosis output pathway.

\section{MATERIALS AND METHODS}

$D R G$ culture. Primary dissociated cultures of E15 dorsal root ganglion neurons were prepared from Sprague Dawley (Harlan Sprague Dawley, Indianapolis, IN) rats using the method previously reported (Eichler and Rich, 1989). Briefly, the DRGs were dissected under aseptic conditions and placed in L-15 medium (Life Technologies, Grand Island, NY). Neurons were dissociated in collagenase and trypsin and then plated on a collagen substratum in a 48 -well plate or on $35 \mathrm{~mm}$ plates. Cell density was $\sim 5000$ cells per well for the 48 -well plates and up to 50,000 cells per 
$35 \mathrm{~mm}$ plate. Cultures were grown in medium that contained $90 \%$ DMEM, $10 \%$ fetal calf serum, $100 \mu \mathrm{g}$ each of penicillin and streptomycin, $20 \mu \mathrm{M}$ each of fluorodeoxyuridine and uridine, $2.0 \mathrm{mM}$ L-glutamine, and $50 \mathrm{ng} / \mathrm{ml}$ of $2.5 \mathrm{~S}$ mouse NGF. Cultures were kept in a $5 \% \mathrm{CO}_{2}$ and $95 \%$ air atmosphere at $37^{\circ} \mathrm{C}$.

Quantitative cell counting. Neurons were fixed with $4 \%$ paraformaldehyde and stained with crystal violet. All neurons in each well were counted, and the counts were averaged.

$N G F$ withdrawal. At the designated time in culture (between 5 and $21 \mathrm{~d}$ ), the neurons were acutely deprived of NGF and treated with $4 \%$ guinea pig serum containing polyclonal antibodies against NGF (supplied by Dr. Eugene Johnson). Cells were fixed (for counting or immunohistochemistry) at designated time points up to $48 \mathrm{hr}$ after NGF deprivation.

High $\mathrm{K}^{+}$media. Neurons normally were maintained in standard medium containing a "physiological" concentration of $\mathrm{K}^{+}(5 \mathrm{mM})$. For some experiments, $5 \mathrm{~d}$ neurons were treated with medium containing an elevated concentration of $\mathrm{K}^{+}(35 \mathrm{~mm})$, which results in depolarization of the cell membrane and a sustained elevation of $\left[\mathrm{Ca}^{2+}\right]_{\mathrm{i}}$ (Tong et al., 1996). Cells were maintained in high $\left[\mathrm{K}^{+}\right]$medium for $24 \mathrm{hr}$ before fixation or lysis.

Quantitative assessment of apoptosis. We used two techniques to assess for evidence of apoptosis. For both techniques, cells were plated on 35 mm plastic Petri dishes modified for UV illumination; a glass coverslip was glued over a $15 \mathrm{~mm}$ diameter hole made in the center of the dish. Cells were fixed in $4 \%$ paraformaldehyde, washed with PBS, and then stained with bis-benzamide (Hoechst 33258; Molecular Probes, Eugene, OR), a fluorescent DNA-binding dye. The cells were viewed at 345/460 $\mathrm{nm}$ wavelengths with a fluorescent microscope (Nikon, Tokyo, Japan) equipped with an ultraviolet filter, and the number of cells showing chromatin condensation were counted. Cells that demonstrated several clumps or densely coalesced nuclei were counted as apoptotic. Nuclear fragments that could not be localized to a cell when viewed under phase-contrast light microscopy were not counted. Three random $200 \times$ fields were counted in this manner. Phase-contrast microscopy was used to determine the total cell count for each field examined; the percentage of cells demonstrating chromatin condensation was calculated.

Cells were also examined for the presence of apoptosis by the method of terminal deoxynucleotidyl transferase-mediated dUTP-biotin nick end-labeling (TUNEL). Cells were washed with PBS and fixed with 4\% paraformaldehyde in PBS for $1 \mathrm{hr}$. They were washed with PBS and blocked for $15 \mathrm{~min}$ in proteinase K. Prelabeling and labeling were performed with a commercially available TUNEL kit used according to the manufacturer's instructions (Trevigen, Gaithersburg, MD). FluoroLink Cy3-streptavidin (Amersham, Buckinghamshire, England) was added at 1:1000 dilution, and the samples were incubated in the dark for 20 min. The samples were washed with PBS and viewed by using a UV light-equipped microscope.

Protein immunoblotting (Western). Cell cultures were washed twice in PBS and lysed in the Petri dish in a protein lysis buffer $(154 \mathrm{~mm} \mathrm{NaCl}$, 39 mm Tris-HCl, pH 7.4, 1\% NP-40, 0.25\% sodium deoxycholate, and 1 mM EGTA) containing protease inhibitors $(1 \mu \mathrm{g} / \mathrm{ml}$ each of leupeptin, aprotinin, and pepstatin; $1 \mathrm{~mm}$ each of $\mathrm{PMSF}, \mathrm{NaF}$, and $\mathrm{Na}_{3} \mathrm{VO}_{4}$ ) or in $1 \times$ loading buffer (2\% SDS, $10 \%$ glycerol, 5\% 2-mercaptoethanol, $0.002 \%$ bromphenol blue, and $0.0625 \mathrm{M}$ Tris $\mathrm{HCl}, \mathrm{pH} 6.8$ ) on ice for 20 min. For the in vivo experiments, dorsal root ganglia were dissected from postnatal day $0,2,4,7,11$, and 19 rat pups. Approximately 10 ganglia were dissected from each pup, and one or two pups were used for each time point. The ganglia were then mechanically lysed in $1 \times$ loading buffer. In all cases, each lysate was centrifuged, and the supernatant was transferred to a fresh microcentrifuge tube. The total protein concentration of each protein lysate was determined by using a modified Bradford reaction (Bio-Rad, Hercules, CA) or with use of the Dotmetric protein assay kit (Geno Technology, St. Louis, MO). Equal amounts of protein from each lysate were loaded on a $15 \%$ SDS-polyacrylamide gel with appropriate protein standards loaded in one well (Amersham). Lysates made with the protein lysis buffer were initially diluted with $2 \times$ Laemmli loading buffer before gel loading. After electrophoresis, the proteins were transferred onto Immobilon-P (Millipore, Bedford, MA) membranes. Each membrane was blocked in nonfat milk $(5 \%)$ in Trisbuffered saline (20 mM Tris, pH 7.5; $150 \mathrm{~mm} \mathrm{NaCl)} \mathrm{with} 0.05 \%$ Tween then blotted with primary antibody followed by an HRP-labeled secondary antibody. The reaction was developed by using ECL or ECL-Plus chemiluminescence reagent (Amersham) and exposed on autoradiography film (Eastman Kodak, Rochester, NY). Bands were digitized and integrated densities determined with use of the NIH Image (version 1.5, National Institutes of Health, Bethesda, MD) software. Membranes were immunoblotted for BAX (clone number 651, 1:500; gift of Dr. S. Korsmeyer) or BCL-X (clone 2A1, 1:2000; gift of Dr. C. Thompson or clone 4, 1:500; Transduction Laboratories, Lexington, KY). Tubulin (clone number DM1A; Sigma, St. Louis, MO) immunoreactivity was used to verify equal protein loading. In one set of experiments we used the PhosphoPlus Akt (Ser473) antibody kit (New England Biolabs, Beverly, MA) according to manufacturer's instructions.

$R T-P C R$. Assessment of the abundance of $b c l-2$ gene family (bcl-2, $b c l-x_{\mathrm{L}}$, bax) transcripts was performed with use of techniques similar to that previously published (Greenlund et al., 1995b). RNA was harvested from cultured DRG neurons, and polyadenylated RNA was isolated using an oligo-dT-cellulose mRNA purification kit (QuickPrep Micro Kit; Pharmacia Biotech, Piscataway, NJ). Half of the poly(A) RNA was converted to cDNA by reverse transcription with Superscript II reverse transcriptase (Life Technologies) with random hexamers $(16 \mu \mathrm{M})$ as primers. PCR was then performed using oligonucleotide primers against bcl- $x_{\mathrm{L}}$ (forward primer, aggctggcgatgatgttgaa; reverse primer, aatgcagcagccgagagccg) and bax (forward primer, tggagctgcagaggatgatt; reverse primer, atgttgctgatggcaactt). Each reaction contained $50 \mu \mathrm{M}$ dCTP, $100 \mu \mathrm{M}$ dGTP, $100 \mu \mathrm{M}$ dATP, $100 \mu \mathrm{M}$ dTTP, $15 \mu \mathrm{Ci}$ of $\left[{ }^{32} \mathrm{P}\right] \mathrm{dCTP}(50 \mu \mathrm{M}), 1.5$ $\mathrm{mm} \mathrm{MgCl}_{2}, 50 \mathrm{~mm} \mathrm{KCl}, 10 \mathrm{~mm}$ Tris, $\mathrm{pH}$ 9.0, 0.1\% Triton X-100, $1 \mathrm{~mm}$ each primer, $1 \mathrm{U}$ of Taq polymerase, and $1 \%$ of the cDNA synthesized in the reverse transcription reaction. We used primers for gapdh (forward primer: cggagtcaacggatttggtcgtat; reverse primer: gtcttcaccaccatggagaaggct) to normalize comparisons between experiments. Each PCR cycle consisted of $1 \mathrm{~min}$ at $94^{\circ} \mathrm{C}, 1 \mathrm{~min}$ at $55^{\circ} \mathrm{C}$, and $2 \mathrm{~min}$ at $72^{\circ} \mathrm{C}$. Products were separated on a $10 \%$ polyacrylamide gel and visualized on a PhosphorImager (Molecular Dynamics, Sunnyvale, CA).

Immunocytochemistry for phosphorylated c-JUN. Cells were plated on $35 \mathrm{~mm}$ Petri dishes modified for UV illumination as described above. At predetermined time points, cells were fixed with $4 \%$ paraformaldehyde in PBS for $30 \mathrm{~min}$ at $4^{\circ} \mathrm{C}$. They were washed three times with TBS and blocked for $30 \mathrm{~min}$ at room temperature (TBS with $5 \%$ goat serum and 0.3\% Triton X-100). Anti-phospho-c-JUN antibody (Ser63; New England Biolabs, Beverly, MA) was added at 1:200 dilution in TBS containing $1 \%$ goat serum and $0.3 \%$ Triton $\mathrm{X}-100$, and incubation was performed overnight at $4^{\circ} \mathrm{C}$. Cells were then washed with TBS three times and incubated in a 1:400 dilution of $\mathrm{Cy} 3$ donkey anti-rabbit antibody (Jackson Immunochemicals, West Grove, PA) in TBS with $1 \%$ goat serum and $0.3 \%$ Triton X-100 for $2 \mathrm{hr}$ at $4^{\circ} \mathrm{C}$. Cells were washed with TBS twice, and Hoeschst $33258(1 \mu \mathrm{g} / \mathrm{ml})$ in TBS was added and allowed to incubate for $20 \mathrm{~min}$ in the dark. Cells were washed with TBS twice and examined using a UV light-equipped microscope.

\section{RESULTS}

\section{Inhibition of PI3K with LY294002}

The effect of inhibition of PI3K on the survival of developing DRG neurons was assessed in vitro. E15 DRG neurons grown in culture for 5 (DIC-5), 10 (DIC-10), or 21 (DIC-21) days were treated with a single dose of LY294002 for $72 \mathrm{hr}$, and the number of surviving neurons was determined. A dose-response curve (Fig. 1) shows loss of $55.7 \%$ of DIC-5 and $30.4 \%$ of DIC-10 neurons at doses of LY294002 up to $10 \mu \mathrm{M}$. Treatment with $25 \mu \mathrm{M}$ LY294002 resulted in loss of nearly all DIC-5 and DIC-10 DRG neurons (97.7 and $99.8 \%$, respectively). In contrast, $53.7 \%$ of DIC-21 DRG neurons survived treatment with doses up to $50 \mu \mathrm{M}$ LY294002. Hence, DIC-21 DRG neurons were significantly more resistant to the lethal effect of LY294002 than were DIC-5 or DIC-10 neurons.

Neurons were assessed further to determine whether treatment with LY294002 produced apoptosis. Treatment with $25 \mu \mathrm{M}$ LY294002 produced chromatin condensation in DIC-5 and DIC-10 DRG neurons. The peak frequency of chromatin condensation, as determined with use of bis-benzamide staining, in LY294002-treated DIC-10 neurons occurred at $24 \mathrm{hr}$ with a magnitude of $\sim 9 \%$ condensation (Fig. 2). Both the time course and magnitude of chromatin condensation after treatment with LY294002 were similar to that observed in DIC-5 and DIC-10 


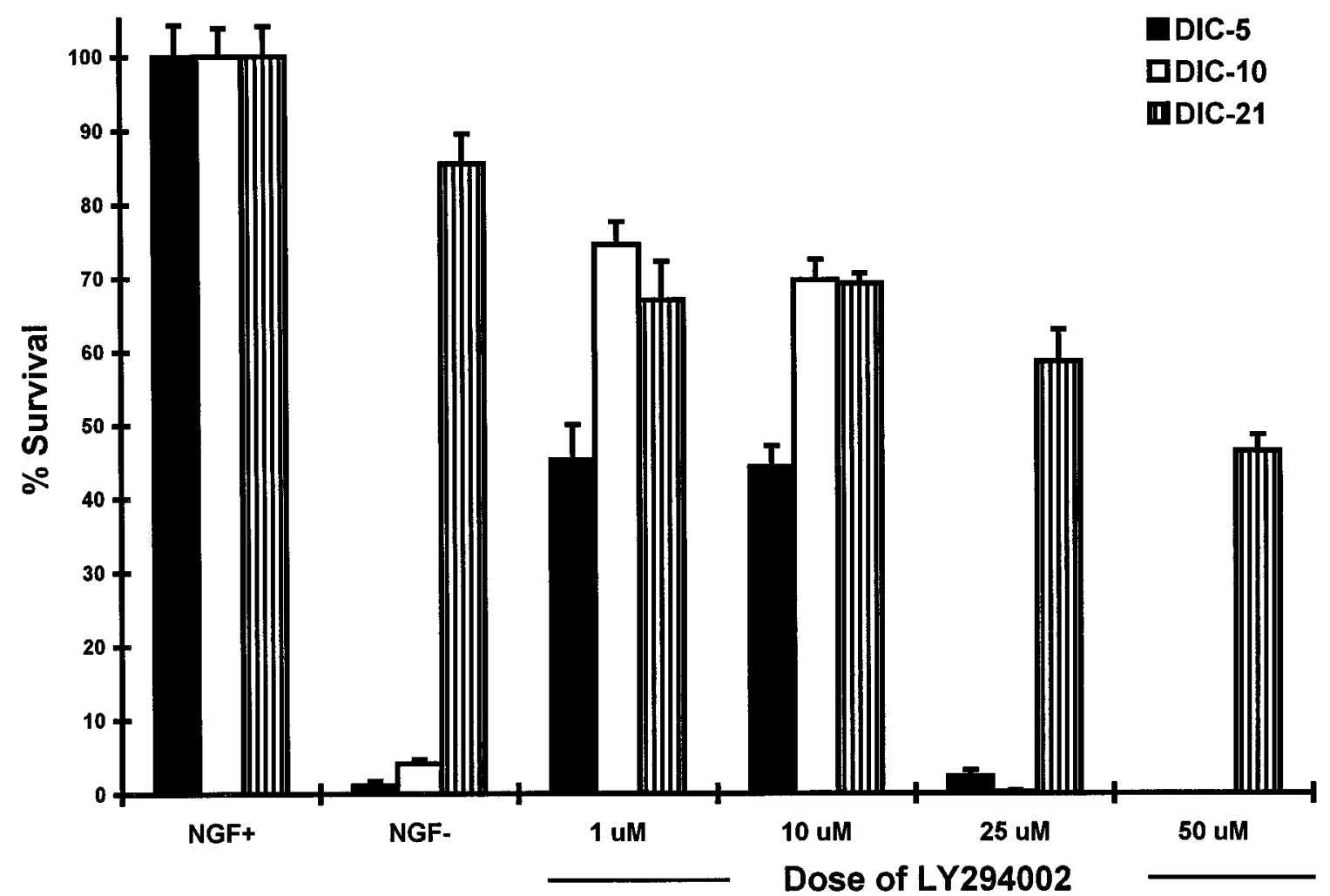

Figure 1. Survival of DRG neurons treated with the phosphotidylinositol-3 kinase inhibitor LY294002. DIC-5, DIC-10, and DIC-21 DRG neurons were treated with doses of LY294002 ranging from 1 to $50 \mu \mathrm{M}$ for $72 \mathrm{hr}$, after which time they were stained with crystal violet and counted. The cell count of each group of wells was normalized to that of wells containing untreated neurons maintained in the presence of NGF, and percent survival was determined. Each value represents the average ( \pm SD) of five wells; $\sim 5000$ DRG neurons were originally plated in each well.

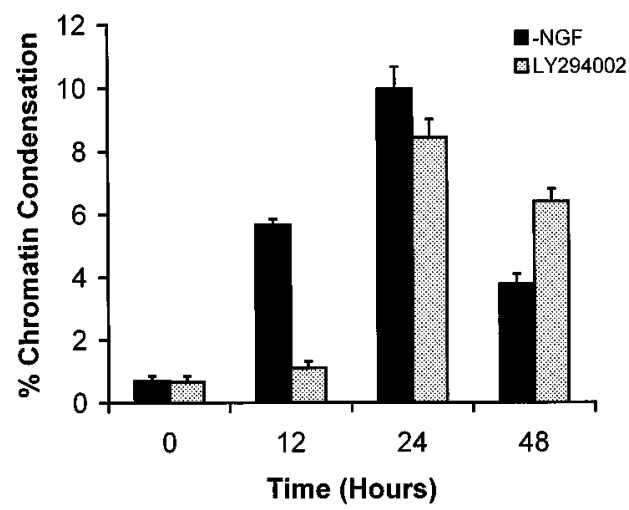

Figure 2. Time course of apoptosis in DIC-10 DRG neurons treated with $25 \mu \mathrm{M}$ LY294002 in the presence of NGF. Neurons were stained with bis-benzamide at the time points indicated and assessed, by fluorescent microscopy, for the presence of chromatin condensation. The percentage of neurons that showed chromatin condensation was determined. Each value represents the average \pm SD of three plates. The number of cells counted for each time point ranged from 488 to 601 . The time course of NGF withdrawal-induced chromatin condensation (data taken from Tong et al., 1996) is shown for comparison purposes.

DRG neurons subjected to NGF withdrawal (Tong et al., 1996). The proapoptotic effect of PI3K inhibition could be blocked by treatment with medium containing elevated $\left[\mathrm{K}^{+}\right]$. Figure 3 shows that treatment of DIC-5 DRG neurons with elevated $\left[\mathrm{K}^{+}\right]$reduced the percentage of cells undergoing chromatin condensation after either treatment with $25 \mu \mathrm{M}$ LY294002 or NGF withdrawal.

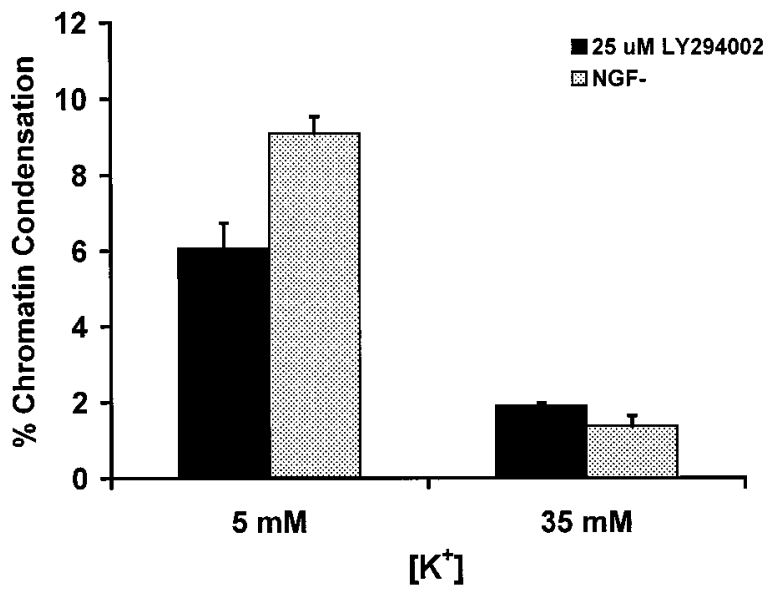

Figure 3. Treatment with elevated $\left[\mathrm{K}^{+}\right]$blocks LY294002-induced apoptosis in DIC-5 DRG neurons. Neurons were maintained in either standard $(5 \mathrm{mM})$ or elevated $(35 \mathrm{mM}) \mathrm{K}^{+}$for $24 \mathrm{hr}$ then treated with $25 \mu \mathrm{M}$ LY294002 or subjected to NGF withdrawal $(N G F-)$. Twenty-four hours later, neurons were stained with bis-benzamide, and the percentage of neurons undergoing chromatin condensation was determined. Each value represents the average \pm SD of three plates. The number of cells counted for each time point ranged from 580 to 678 .

Hence, LY294002-induced apoptosis could be inhibited by elevated $\left[\mathrm{K}^{+}\right]$in a manner similar to that observed after NGF withdrawal.

We used a second assay for apoptosis (TUNEL) to examine the relationship between the dose of LY294002 and magnitude of the 


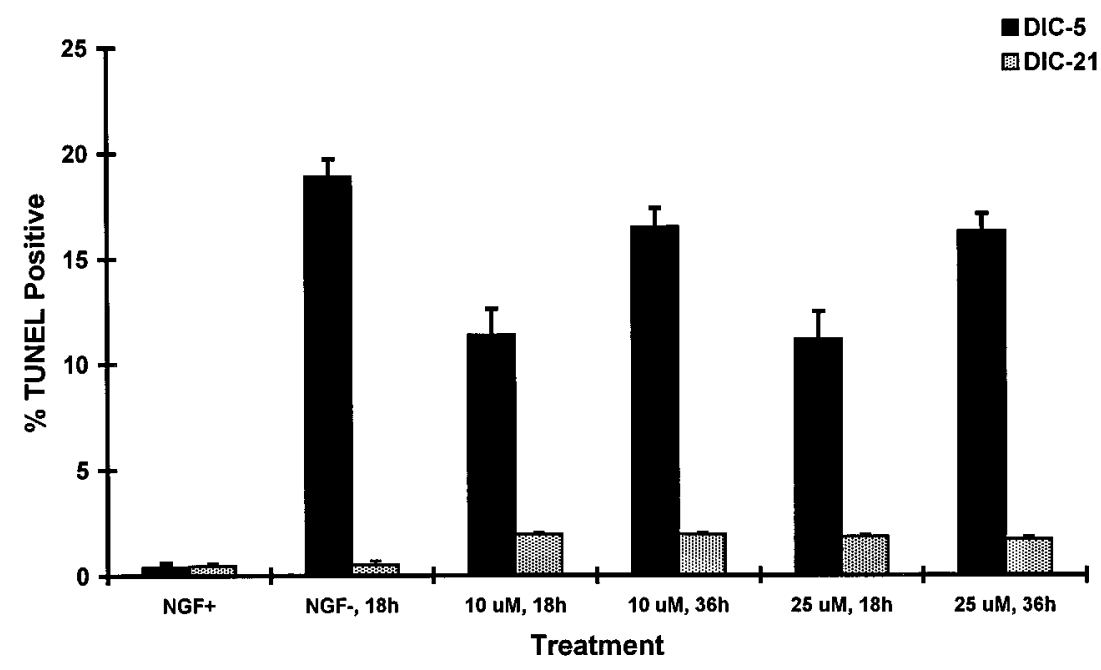

Figure 4. Induction of apoptosis by treatment with LY294002. DIC-5 and DIC-21 DRG neurons were treated with either 10 or $25 \mu \mathrm{M}$ doses of LY294002 for either 18 or $36 \mathrm{hr}$ and then assessed for TUNELpositive staining. Induction of apoptosis by NGF withdrawal was also performed for comparison purposes $(N G F-)$. The percentage of neurons that showed TUNEL-positive staining was determined. Each value represents the average $\pm \mathrm{SD}$ of three plates. The number of cells counted for each time point ranged from 578 to 720 .
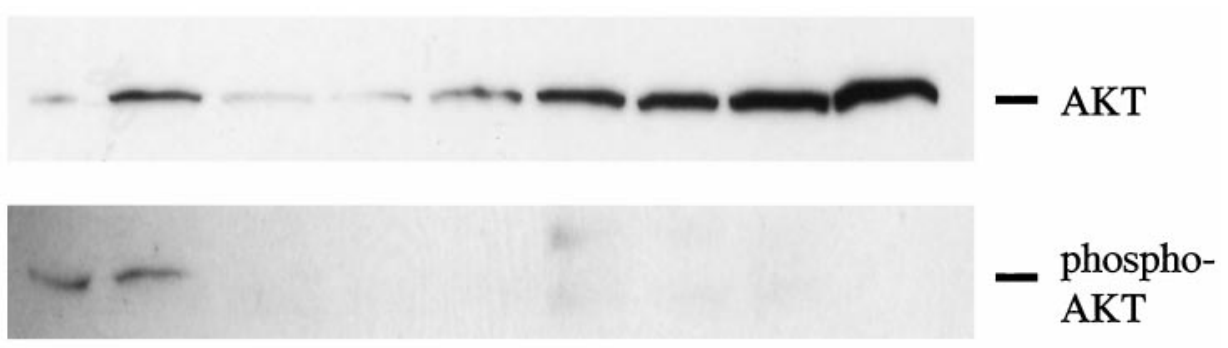
1
23
3
DIC-7
$\sqrt{5}$
$\begin{array}{lll}6 & 7 & 8\end{array}$
9
DIC-21

Figure 5. Treatment of DRG neurons with LY294002 blocks AKT activation. DIC-5 and DIC-21 neurons were maintained in the presence of NGF (lanes 2 and 6), subjected to NGF withdrawal (lanes 3 and 7), or treated with 5 (lanes 4 and 8 ) or 10 (lanes 5 and 9) $\mu \mathrm{M}$ LY294002 in the presence of NGF for $18 \mathrm{hr}$ before lysis. Equal amounts of protein were loaded on $15 \%$ polyacrylamide gels and separated by SDS-PAGE. Proteins were transferred to PVDF membranes, and then each membrane was Western blotted individually for total AKT (top) or Ser473-phosphorylated AKT (bottom) using the PhosphoPlus Akt antibody kit (New England Biolabs). Controls $(C$, lane 1$)$ provided with the kit consisted of total cell extracts from National Institutes of Health 3 T3 cells grown in the presence (bottom) and absence (top) of PDGF. apoptotic response in developing DRG neurons. Treatment of DIC-5 DRG neurons with a $10 \mu \mathrm{M}$ concentration of LY294002 produced positive TUNEL staining in $11.4 \%$ of neurons at $18 \mathrm{hr}$ and $16.5 \%$ of neurons at $36 \mathrm{hr}$ (Fig. 4). No increase in the percentage of TUNEL-positive cells was observed when the dose of LY294002 was increased to $25 \mu \mathrm{M}$. In contrast, $<2 \%$ of DIC-21 DRG neurons treated with 10 or $25 \mu \mathrm{M}$ LY294002 were TUNELpositive at 18 or $36 \mathrm{hr}$ after treatment. We also examined whether DIC-21 neurons underwent apoptosis after treatment with both NGF withdrawal and $25 \mu \mathrm{M}$ LY294002. No significant difference in percentage of neurons undergoing DNA condensation was observed compared with treatment with LY294002 alone (0.82 vs $0.90 \% ; p=0.52$ ). Hence, inhibition of PI3K activity produced apoptosis in DIC-5 but not DIC-21 DRG neurons.

We confirmed that LY294002 inhibited PI3K activity by examining the phosphorylation status of AKT. AKT (which is also referred to as protein kinase B) is the downstream target of PI3K in the NGF-dependent survival pathway (Datta et al., 1997; Dudek et al., 1997; Kennedy et al., 1997). Figure 5 shows that doses as low as 5 and $10 \mu \mathrm{M}$ LY294002 were sufficient to completely block phosphorylation of AKT in DIC-5 neurons. This result is consistent with the finding that no additional TUNEL-positive staining was observed with doses $>10 \mu \mathrm{M}$ LY294002. We further noted that there was no phosphorylation of AKT in the DIC-21 neurons, even in the presence of NGF, despite an increase in the total amount of AKT produced by these cells.

\section{Activation of c-JUN in apoptotic DRG neurons}

NGF withdrawal results in activation of c-JUN in DRG neurons. Immunohistochemical techniques were used to assess the relative levels of c-JUN expression and phosphorylation in DIC-5 and DIC-21 DRG neurons at various times ranging from 3 to $18 \mathrm{hr}$ after NGF withdrawal. DIC-5 DRG neurons grown in the presence of NGF did not express detectable levels of phosphorylated c-JUN. After NGF deprivation, however, the majority of DRG neurons were immunoreactive for phosphorylated c-JUN (Fig. $6 A, D)$. Positive immunostaining for phosphorylated c-JUN was strongest at 12 and $18 \mathrm{hr}$ after NGF withdrawal. Activation of c-JUN also occurred in DIC-5 neurons treated with high $\mathrm{K}^{+}$ medium and NGF withdrawal, despite the fact that these neurons did not subsequently undergo apoptosis (Fig. 6B,E). Similarly, DIC-21 DRG neurons were not immunoreactive for phosphorylated c-JUN in the presence of NGF but became strongly immunoreactive in its absence (Fig. $6 C, F$ ). c-JUN phosphorylation was also observed in both DIC-5 and DIC-21 DRG neurons after treatment with LY294002 (Fig. 7). Thus, c-JUN phosphorylation occurred when cells were treated with NGF withdrawal or LY294002, but the activation of c-Jun was not correlated with apoptosis in all cases.

\section{Developmental changes in expression of BCL-2 family members}

To address the hypothesis that a change in sensitivity to NGF withdrawal could be caused by a developmental change in the 


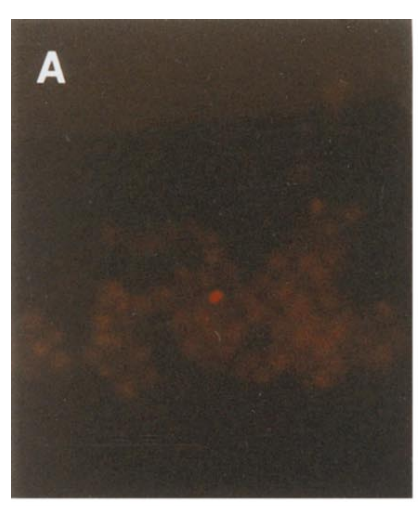

Figure 6. Ser-63 phosphorylation of c-JUN in DRG neurons subjected to NGF withdrawal. DIC-5 $(A, B, D, E)$ and DIC-21 $(C, F)$ DRG neurons were maintained in the presence $(A-C)$ or absence $(D-F)$ of NGF for $18 \mathrm{hr}$ after which they were fixed in $4 \%$ paraformaldehyde. Immunofluorescent staining for Ser-63-phosphorylated c-JUN was performed, and neurons were examined with the use of fluorescent microscopy. Positive staining for Ser-63 phosphorylation of c-JUN consists of dense, nuclear immunoreactivity, and is seen only in $D-F$. Ser-63 phosphorylation of c-JUN is not blocked by treatment with high $\left[\mathrm{K}^{+}\right]$medium $(E)$.
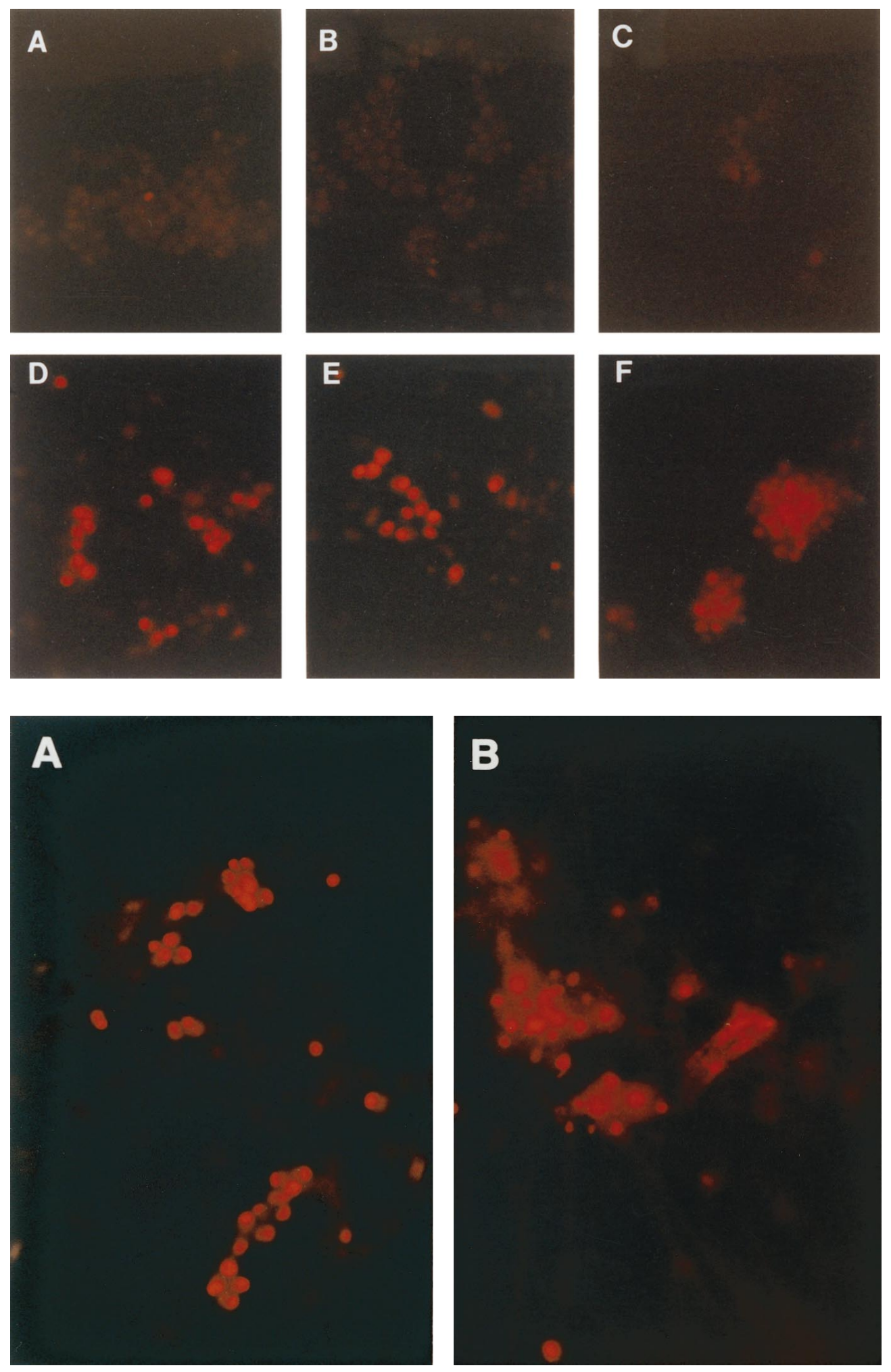

tectable level over the time period examined (Fig. $8 B$ ). However, $\mathrm{BCL}-\mathrm{X}$ expression rose considerably more in vivo than in vitro during the first 19 postnatal days (Fig. 8B). The net result was a more marked increase in vivo in the BCL-X/BAX ratio over this time period.

To examine whether regulation occurred at the transcriptional or translational level, we performed RT-PCR analysis of bax and $b c l-x_{\mathrm{L}}$ mRNA levels in DIC-5 and DIC-21 DRG neurons main- ratio increased approximately fivefold. Similarly, BAX expression in dorsal root ganglia in vivo decreased progressively to an unde- apoptosis effector pathway we examined the level of expression in DRG neurons, both in vitro and in vivo, of BAX and BCL-X by Western blot analysis. In DRG neurons maintained in the presence of NGF in vitro, BAX expression decreased, and BCL-X expression increased moderately between 5 and $21 \mathrm{~d}$ (Fig. 8A). Quantification of these bands revealed that the BCL-X/BAX 
A

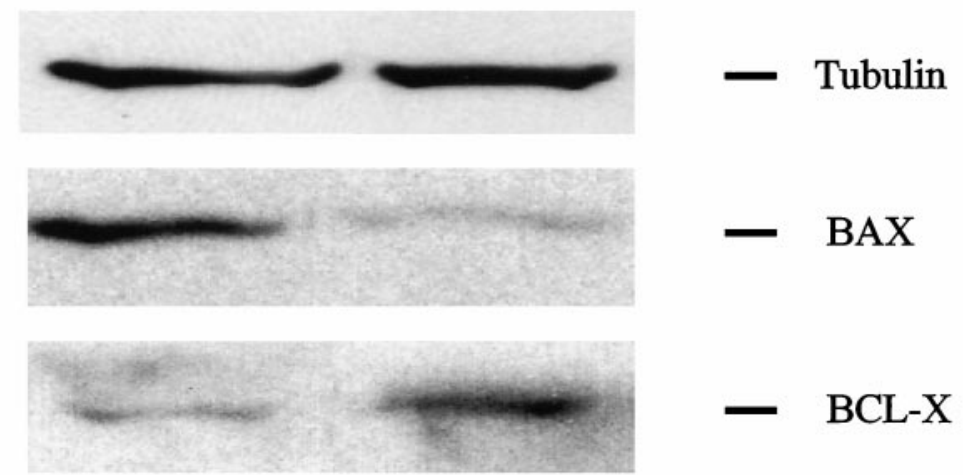

DIC-5 DIC-21

B

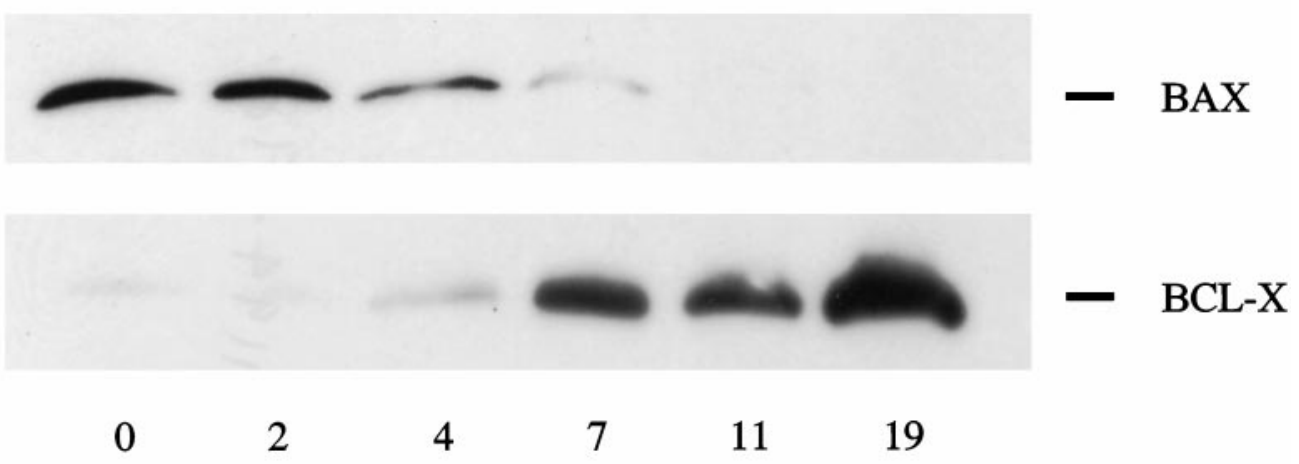

Post-Natal Day Number

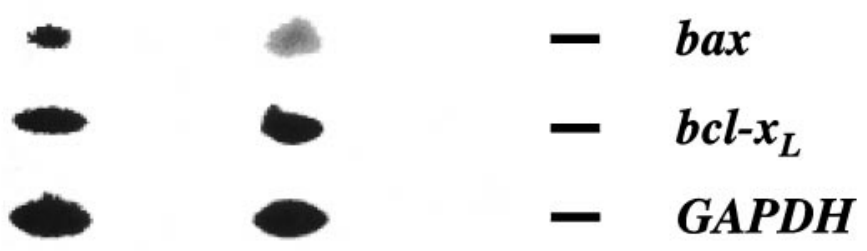

\section{DIC-5 DIC-21}

Figure 9. Developmental regulation of bax and $b c l-x_{\mathrm{L}}$ transcription. Polyadenylated RNA was isolated from DIC-5 and DIC-21 DRG neurons maintained in medium containing NGF. Quantitative RT-PCR was performed with use of gapdh mRNA levels as a separate, internal control. Multiple cDNA dilutions and cycle numbers were used to determine the linear PCR range. Radiolabeled PCR products were separated on $10 \%$ polyacrylamide gels and visualized on a PhosphorImager. Shown are representative examples of PCR products obtained. Quantitation of each band was performed using ImageQuant, and the ratios of $b a x / b c l-x_{\mathrm{L}}$ mRNA are shown. These results are representative of four independent experiments.

tained in vitro. Figure 9 demonstrates the changes that occurred in bax and $b c l-x_{\mathrm{L}}$ message levels in developing DRG neurons. Between days 5 and 21, in the presence of NGF, bax mRNA levels fell by $\sim 65 \%$, and $b c l-x_{\mathrm{L}}$ levels increased by $\sim 56 \%$ resulting in a nearly fivefold increase in the $b c l-x_{\mathrm{L}} /$ bax ratio.
Figure 8. A, Western blot analysis of BAX and BCL-X expression in developing DRG neurons. Protein was isolated from DIC-5, and DIC-21 was maintained in the presence of NGF. Equal amounts of protein $(25 \mu \mathrm{g} /$ lane $)$ were loaded on $15 \%$ polyacrylamide gels and separated by SDS-PAGE. Proteins were transferred to PVDF membranes, which were then immunoblotted for BAX or BCL-X expression. These blots are representative of three independent experiments. $B$, Western blot analysis of BAX and BCL-X expression in dorsal root ganglia of postnatal rats $(50 \mu \mathrm{g}$ of total protein/lane). Methods as in $A$.

\section{DISCUSSION}

Developing DRG neurons have a well characterized loss of dependence for survival on their major trophic factor input, NGF. In NGF-dependent neurons, apoptosis after NGF withdrawal requires inactivation of $\mathrm{PI} 3 \mathrm{~K}$, activation of c-JUN, and the expression of bax at an appropriate level (Estus et al., 1994; Ham et al., 1995; Yao and Cooper, 1995; Deckwerth et al., 1996). Of these three important elements associated with apoptosis after NGF withdrawal in vitro, only the relative level of expression of bax was altered during development to render the neurons NGFindependent. In addition, we found the relative level of expression of $b c l-x_{\mathrm{L}}$ to be under developmental control.

The survival-promoting effect of NGF requires activation of PI3K in many types of neurons. Inhibition of PI3K with wortmannin or LY294002 (Vlahos et al., 1994) induces apoptosis in the presence of NGF with a time course similar to that observed after serum withdrawal in PC12 cells (Yao and Cooper, 1995). A similar role of PI3K has been shown in cerebellar granule cells in which PI3K is activated by insulin-like growth factor 1 binding (D'Mello et al., 1997). There is conflicting evidence regarding whether this critical role for PI3K can be extended to primary superior cervical ganglion (SCG) neurons, however (Philpott et al., 1997; Crowder and Freeman, 1998). Our results in primary cultures of DRG neurons are consistent with the role of PI3K in PC12 cells and many other cell types (Scheid et al., 1995; Vemuri and McMorris, 1996). 
Treatment of either DIC-5 or DIC-21 DRG neurons with LY294002 resulted in a dose-dependent, stepwise decrease in survival. However, DIC-21 DRG neurons were less sensitive to this drug than were DIC-5 neurons. Treatment with LY294002 resulted in activation of apoptotic pathways in DIC-5 but not in DIC-21 neurons. LY294002-induced apoptosis in these neurons was blocked by increased $\left[\mathrm{K}^{+}\right]$in the medium, a finding that is also characteristic of NGF withdrawal-mediated apoptosis. The death of DIC-21 DRG neurons resulting from treatment with LY294002 did not occur via apoptosis. The finding of no significant increase in apoptosis in DIC-21 neurons after treatment with both NGF withdrawal and LY294002 supports our conclusion that LY294002 produced a nonapoptotic form of death in these neurons.

To confirm that LY294002 blocked PI3K, we examined the ability of this drug to block phosphorylation of the serine-threonine kinase AKT. AKT is a downstream target of PI3K and a member of the NGF signaling pathway involved in cell survival (Datta et al., 1997; Dudek et al., 1997; Kennedy et al., 1997). Activation of AKT can occur by phospholipid binding and by phosphorylation at both Ser473 and at Thr308, which is mediated by PI3K (Alessi et al., 1996). In DIC-5 neurons we found that treatment with as little as $5 \mu \mathrm{M}$ LY294002 produced loss of AKT Ser473 phosphorylation. The effect of inhibition of PI3K, with use of a relatively low dose of LY294002, was the apoptotic death of DIC-5 but not DIC-21 DRG neurons. Hence, there is no evidence to support the hypothesis that PI3K activity is developmentally upregulated in mature DRG neurons.

The PI3K pathway may not be the only pathway used to carry the NGF survival signal, however. We found that a relatively low dose of LY294002 (10 $\mu \mathrm{M})$ was sufficient to prevent AKT Ser473 phosphorylation but that it did not produce the same percentage of cell death or TUNEL-positive cells as did NGF withdrawal (Figs. 1, 4). A higher dose of LY294002 (25 $\mu \mathrm{M})$ was lethal to an greater percentage of cells but produced no more TUNELpositive staining. Hence, inhibition of PI3K alone could not produce the same percentage of apoptosis as did NGF withdrawal. One possible explanation for this discrepancy is that additional pathways carry the NGF survival signal independent of the PI3K pathway. However, none of the known pathways downstream of TRK activation by NGF has been shown to carry the survival signal in SCG neurons (Philpott et al., 1997).

Another well studied member of the NGF withdrawal signal transduction pathway is c-JUN. NGF withdrawal results in increased production of c-JUN in SCG neurons before the onset of apoptosis (Estus et al., 1994; Ham et al., 1995). The necessity of c-JUN induction for NGF withdrawal-induced apoptosis was demonstrated by the protective effect of anti-c-JUN antibody treatment and a c-Jun-dominant negative mutant (Estus et al., 1994; Ham et al., 1995).

c-JUN phosphorylation occurred in both DIC-5 and DIC-21 DRG neurons after NGF withdrawal despite the fact that DIC-21 neurons did not subsequently undergo apoptosis. If developmental regulation of apoptosis had occurred at a point early in the NGF signal transduction pathway, we would have expected to observe a loss of c-JUN phosphorylation after NGF withdrawal. Our result is consistent with the finding that c-JUN phosphorylation occurs in NGF-deprived SCG neurons from bax knock-out mice that do not undergo apoptosis (Deckwerth et al., 1997). This result also supports the conclusion that developmental regulation of the NGF withdrawal signal input pathway does not occur upstream of c-JUN phosphorylation, whether it be at the level of
PI3K activation or by mediation of alternative signal transduction pathways.

Further downstream, activation of the apoptosis pathway requires the presence of BAX (Deckwerth et al., 1996). In general, members of the $b c l-2$ gene family regulate sensitivity of cells to apoptosis. Three important members of this family are $b c l-2$ (Hockenbery et al., 1993), bcl-x (which produces long and short transcripts, Boise et al., 1993), and bax (Oltvai et al., 1993). Increased expression of antiapoptotic $\left(b c l-2, b c l-x_{1}\right)$ or loss of proapoptotic (bax, bcl- $x_{\mathrm{s}}$ ) gene expression delays or prevents apoptosis after trophic factor withdrawal (Garcia et al., 1992; Greenlund et al., 1995b; Deckwerth et al., 1996; Gillardon et al., 1996). Conversely, loss of antiapoptotic gene expression enhances neuronal loss (Greenlund et al., 1995a; Roth et al., 1996). Overexpression of the proapoptotic gene bax results in increased sensitivity to trophic factor withdrawal in SCG neurons (Easton et al., 1997). We chose to examine the expression of bax and $b c l-x_{\mathrm{L}}$ only because previous work suggests strongly that these are the critical genes that play a significant role in determining apoptosis in DRG development. The development of trophic factor independence in DRG neurons is unaffected by loss of bcl-2 (Greenlund et al., 1995b). In contrast, neurons from bax (-/-) knock-out mice are resistant to apoptosis after NGF withdrawal (Deckwerth et al., 1996), and extensive neuronal apoptosis is observed in utero in $b c l-x(-/-)$ knock-out mice (Motoyama et al., 1995).

It has been proposed that the balance of expression of proapoptotic to antiapoptotic genes determines sensitivity to apoptosis-inducing insults (Oltvai and Korsmeyer, 1994). In neurons of the CNS, BAX levels decrease 20- to 140-fold from the neonatal period to adulthood, but BCL-X levels remain unchanged (Vekrellis et al., 1997). In contrast, SCG neurons show no change in $b c l-x$ or bax mRNA (Greenlund et al., 1995b) or protein (Easton et al., 1997) levels during development. However, past work has shown that sympathetic neurons do not lose dependence on NGF for survival in a manner similar to that observed in DRG neurons. Greene (1977a,b) showed that mature SCG but not DRG neurons in vitro remained sensitive to NGF withdrawal up to $30 \mathrm{~d}$ in culture. Rich et al. (1984) showed a similar differential sensitivity in an in vivo model of NGF deprivation. Hence, observations concerning the regulation of $\mathrm{bcl}-2$ family members in SCG neurons may not apply to DRG neurons.

At both the translational and transcriptional levels, expression of bax is regulated as DRG neurons mature. We also found that the relative level of expression of $b c l-x_{\mathrm{L}}$ is under developmental control. DIC-5 DRG neurons have a high ratio of BAX/BCL-X, which correlates with a high degree of dependence on NGF for survival. As these neurons age, the expression of these proteins progressively changes with a net result that DIC-21 DRG neurons have a many-fold lower ratio of expression of these proteins. The change in the BAX/BCL-X ratio was more dramatic in vivo, where a much stronger increase in BCL-X expression was observed as the animals matured. The decreased $\mathrm{BAX} / \mathrm{BCL}-\mathrm{X}$ ratio correlates with the developmental point at which DRG neurons are relatively insensitive to NGF withdrawal, and it is sufficient to explain the loss of sensitivity of these neurons to trophic factor deprivation (and to other insults such as treatment with ionizing radiation, see Tong et al., 1997).

The time course of the in vivo change in the BAX/BCL-X ratio was similar to that observed in vitro. Previous work in our laboratory has demonstrated that the developmental loss of NGF dependence is determined by the absolute age of the neurons, not 
the relative age in culture (Eichler and Rich, 1989). Postnatal day 0 in rats corresponds to embryonic day 22. Hence, the loss of BAX expression by postnatal day 11 is temporally consistent with our finding that BAX expression is lost in vitro by DIC-19 (data not shown).

In conclusion, the molecular basis for a change in sensitivity to trophic factor withdrawal in developing DRG neurons does not involve modulation of PI3K or c-JUN activity, which are key components of the signal transduction pathway. In contrast, we found a fivefold decrease in the BAX/BCL-X ratio, both on the transcriptional and translational level, in developing DRG neurons that correlated temporally with loss of trophic factor dependence in vitro. An even more dramatic decrease in the BAX/ $\mathrm{BCL}-\mathrm{X}$ ratio was observed in DRG neurons in vivo. Hence, aspects of the developmental regulation of trophic factor withdrawal-induced apoptosis in DRG neurons appear to occur at the level of regulation of members of the $b c l-2$ gene family.

\section{REFERENCES}

Alessi DR, Andjelkovic M, Caudwell B, Cron P, Morrice N, Cohen P, Hemmings BA (1996) Mechanism of activation of protein kinase B by insulin and IGF-1. EMBO J 15:6541-6551.

Boise LH, Gonzalez-Garcia M, Postema CE, Ding L, Lindstein T, Turka LA, Mao X, Nunez G, Thompson CB (1993) bcl-x, a bcl-2 related gene that functions as a dominant regulator of apoptotic cell death. Cell 74:597-608.

Crowder RJ, Freeman RS (1998) Phosphatidylinositol 3-kinase and Akt protein kinase are necessary and sufficient for the survival of nerve growth factor-dependent sympathetic neurons. J Neurosci 18:2933-2943.

Datta SR, Dudek H, Tao X, Masters S, Fu H, Gotoh Y, Greenberg ME (1997) Akt Phosphorylation of BAD couples survival signals to the cell-intrinsic death machinery. Cell 91:231-241.

Deckwerth TL, Elliott JL, Knudson CM, Johnson Jr EM, Snider WD, Korsmeyer SJ (1996) BAX is required for neuronal death after trophic factor deprivation and during development. Neuron 17:401-411.

Deckwerth TL, Easton RM, Knudson CM, Korsmeyer SJ, Johnson Jr EM (1997) Placement of the BCL-2 family member BAX in the death pathway activated by NGF deprivation of sympathetic neurons. Soc Neurosci Abstr 23:772.9.

D’Mello SR, Borodezt K, Soltoff SP (1997) Insulin-like growth factor and potassium depolarization maintain neuronal survival by distinct pathways: possible involvement of PI 3-kinase in IGF-1 signaling. J Neurosci 17:1548-1560.

Dudek H, Datta SR, Franke TF, Birnbaum MJ, Yao R, Cooper GM, Segal RS, Kaplan DR, Greenberg ME (1997) Regulation of neuronal survival by the serine-threonine protein kinase Akt. Science 275:661-665.

Easton RM, Deckwerth TL, Parsadanian Ash, Johnson Jr EM (1997) Analysis of the mechanism of loss of trophic factor dependence associated with neuronal maturation: a phenotype indistinguishable from BAX deletion. J Neurosci 17:9656-9666.

Eichler ME, Rich KM (1989) Death of sensory ganglion neurons after acute withdrawal of nerve growth factor in dissociated cell cultures. Brain Res 482:340-346.

Estus S, Zaks WJ, Freeman RS, Gruda M, Bravo R, Johnson Jr EM (1994) Altered gene expression in neurons during programmed cell death: identification of c-jun as necessary for neuronal apoptosis. J Cell Biol 127:1717-1727.

Garcia I, Martinou I, Tsujimoto Y, Martinou JC (1992) Prevention of programmed cell death of sympathetic neurons by the bcl-2 protooncogene. Science 258:302-304.

Gillardon F, Zimmermann M, Uhlmann E, Krajewski S, Reed JC, Klimaschewski L (1996) Antisense oligodeoxynucleotides to bax mRNA promote survival of rat sympathetic neurons in culture. J Neurosci Res 43:726-734.

Greene LA (1977a) Quantitative in vitro studies on the nerve growth factor (NGF) requirement of neurons. I. Sympathetic neurons. Dev Biol 58:96-105.
Greene LA (1977b) Quantitative in vitro studies on the nerve growth factor (NGF) requirement of neurons. II. Sensory neurons. Dev Biol 58:106-113.

Greenlund LJS, Deckwerth TL, Johnson Jr EM (1995a) Superoxide dismutase delays neuronal apoptosis: a role for reactive oxygen species in programmed neuronal death. Neuron 14:303-15.

Greenlund LJS, Korsmeyer SJ, Johnson Jr EM (1995b) Role of BCL-2 in the survival and function of developing and mature sympathetic neurons. Neuron 15:649-661.

Ham J, Babij C, Whitfield J, Pfarr CM, Lallemand D, Yaniv M, Rubin LL (1995) A c-Jun dominant negative mutant protects sympathetic neurons against programmed cell death. Neuron 14:927-939.

Hamburger V, Yip JW (1984) Reduction of experimentally induced neuronal death in spinal ganglia of the chick embryo by nerve growth factor. J Neurosci 4:767-774.

Hockenbery DM, Nunez G, Milliman C, Schreiber RD, Korsmeyer SJ (1993) Bcl-2 functions in an antioxidant pathway to prevent apoptosis. Cell 75:241-251.

Johnson Jr EM, Gorin PD, Brandeis LD, Pearson J (1980) Dorsal root ganglion neurons are destroyed by exposure in utero to maternal antibody to nerve growth factor. Science 210:916-918.

Johnson Jr EM, Rich KM, Yip HK (1986) The role of NGF in sensory neurons in vitro. Trends Neurosci 9:33-37.

Kennedy SG, Wagner AJ, Conzen SD, Jordan J, Bellacosa A, Tsichlis PN, Hay N (1997) The PI3-kinase/Akt signaling pathway delivers an antiapoptotic signal. Genes Dev 11:701-713.

Kerr JFR, Wyllie Ah, Currie AR (1972) Apoptosis: a basic biological phenomenon with wide-ranging implications in tissue kinetics. $\mathrm{Br} \mathrm{J}$ Cancer 26:239-257.

Motoyama N, Wang F, Roth KA, Sawa H, Nakayama K, Nakayama K, Negishi I, Senju S, Zhang Q, Fujii S, et al (1995) Massive cell death of immature hematopoietic cells and neurons in Bcl-x-deficient mice. Science 267:1506-1510.

Oltvai ZN, Korsmeyer SJ (1994) Checkpoints of dueling dimers foil death wishes. Cell 79:189-192.

Oltvai ZN, Milliman CL, Korsmeyer SJ (1993) bcl-2 heterodimerizes in vivo with a conserved homolog, bax, that accelerates programmed cell death. Cell 74:609-619.

Oppenheim RW (1985) Naturally occurring cell death during neurodevelopment. Trends Neurosci 8:487-493.

Oppenheim RW (1991) Cell death during development of the nervous system. Annu Rev Neurosci 14:453-501.

Philpott KL, McCarthy MJ, Klippel A, Rubin LL (1997) Activated phosphatidylinositol 3-kinase and Akt kinase promote survival of superior cervical neurons. J Cell Biol 139:809-815.

Rich KM, Yip HK, Osborne PA, Schmidt RE, Johnson Jr EM (1984) Role of nerve growth factor in the adult dorsal root ganglia neuron and its response to injury. J Comp Neurol 230:110-118.

Roth KA, Motoyama N, Loh, DY (1996) Apoptosis of bcl-x deficient telencephalic cells in vitro. J Neurosci 16:1753-1758.

Scheid MP, Lauener RW, Duronio V (1995) Role of phosphatidylinositol 3-OH-kinase activity in the inhibition of apoptosis in haemopoetic cells: phosphatidylinositol 3-OH kinase inhibitors reveal a difference in signaling between interleukin-3 and granulocyte-macrophage colony stimulating factor. Biochem J 312:159-162.

Tong JX, Eichler ME, Rich KM (1996) Intracellular calcium levels influence apoptosis in mature sensory neurons after trophic factor deprivation. Exp Neurol 138:45-52.

Tong JX, Vogelbaum MA, Dryzmala R, Rich KM (1997) Radiationinduced apoptosis in post-mitotic DRG neurons. J Neurocytol 26:771-777.

Vekrellis K, McCarthy MJ, Watson A, Whitfield J, Rubin LL, Ham J (1997) Bax promotes neuronal cell death and is downregulated during the development of the nervous system. Development 124:1239-1249.

Vemuri GS, McMorris FA (1996) Oligodendrocytes and their precursors require phosphatidylinositol 3-kinase signaling for survival. Development 122:2529-2537.

Vlahos CJ, Matter WF, Hui KY, Brown RF (1994) A specific inhibitor of phosphatidylinositol 3-kinase, 2-(4-morpholinyl)-8-phenyl-4H-1benzopyran-4-one (LY294002). J Biol Chem 269:5241-5248.

Yao R, Cooper GM (1995) Requirement for phosphatidylinositol-3 kinase in the prevention of apoptosis by nerve growth factor. Science 267:2003-2006. 